\title{
Incidence of facial pressure ulcers following surgery in the prone position - experience in a tertiary care hospital
}

\author{
Xi Wern Ling ${ }^{1 *}$, Sitaram K Raman', Jerry Keng Tiong Tan ${ }^{3}$, Ying $\mathrm{Hao}^{4}$, Kah Ming Saw ${ }^{5}$ \\ Resident $^{*}$, Senior Consultant ${ }^{2}$, Consultant ${ }^{3}$, Associate Consultant ${ }^{5}$, Department of Anaesthesiology, \\ Singapore General Hospital, Singapore. Research Fellow ${ }^{4}$, Health Services Research Unit, Singapore \\ General Hospital, Singapore.
}

Introduction: The development of facial pressure ulcers after prone positioning is a well-known complication and a common source of patient dissatisfaction. Several risk factors have been identified in past studies. However, few studies have focused on the Asian population. We therefore set forth to identify the incidence of facial pressure ulcers following surgery in the prone position in our local population, as well as determine possible risk factors for their development.

Methods: We recruited 132 patients who underwent elective surgery in a prone position under general anaesthesia in our tertiary hospital. The occurrence of facial pressure ulcers was analysed against several demographic and intraoperative factors. Statistical significance was taken as $p<0.05$.

Results: A total of 114 patients were included in the final analysis. The overall incidence of facial pressure ulcers was $35 \%$. The most common locations were the cheeks $(75 \%)$, and the forehead $(43 \%)$. Increased age (OR 1.04 per year, $\mathrm{p}=0.035)$ and a prolonged duration of surgery (OR 2.05 per hour, $\mathrm{p}<0.001$ ) were both significantly associated with facial pressure ulcers.

Conclusion: Facial pressure ulcers are common following surgery in a prone position in our local context. This first study on the Southeast Asian population corroborates with known risk factors for pressure ulcer development. Future studies may explore possible risk reduction measures to reduce the incidence of facial pressure ulcers in Southeast Asian populations.

Keywords: prone; pressure ulcers; facial ulcers; general anaesthesia

\section{Introduction}

Pressure ulcers are a well-recognised complication in patients undergoing surgery in a prone position. Past literature has reported an incidence varying from 0.3 to $57.4 \%$. Facial pressure ulcers can cause cosmetic disfigurement and are a significant source of patient dissatisfaction. ${ }^{1}$

To date, several risk factors have been identified. Preoperative risk factors include female gender, increased age, extremes of body mass index (BMI), higher American Society of Anaesthesiologists (ASA) status, prior chronic

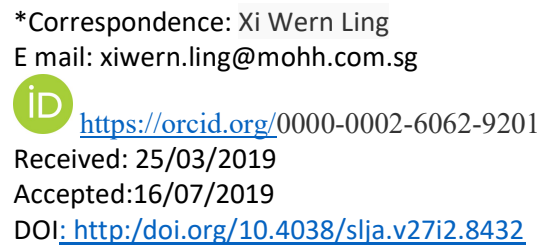

steroid use, chronic smoking and presence of peripheral vascular disease, diabetes mellitus (DM) and low serum albumin. Intraoperative risk factors include prolonged surgery and hypotensive episodes. ${ }^{1-4}$

However, most studies were conducted in Caucasian populations with a dearth of studies examining Asian populations more relevant to our local practice. We therefore set forth to examine as our primary outcome the incidence of facial pressure ulcers in patients undergoing surgery in the prone position in our local setting and ascertain if similar risk factors apply to our local population.

\footnotetext{
Methods

Approval and waiver of consent was obtained from our institution's Centralised Institutional Review Board prior to the commencement of our study.
} 
We conducted a prospective observational study in our tertiary hospital starting from August 2015. The study was concluded in May 2016 after we recruited a total of 132 patients.

The primary outcome investigated was the occurrence of new facial pressure ulcers as identified according to the National Pressure Ulcer Advisory Panel (NPUAP) staging system. ${ }^{5}$

Based on an expected incidence of facial pressure ulcers between $0.3 \%$ to $57.4 \%$ as reported in past literature, we determined that a minimum sample size of 100 patients would be required to obtain an estimate within $\pm 10 \%$ of the true population incidence with a confidence level of $95 \%$. Factoring in an arbitrary dropout rate of $20 \%$ for inadequately filled forms, we aimed to recruit 130 patients to allow for a final analysis of at least 100 patients.

All elective surgeries done under general anaesthesia during office hours in the major operating theatre and urology complex were included. We excluded patients who underwent emergency surgery, those who underwent surgery out of office hours as well as those who had surgery outside the above-mentioned locations. All patients who met inclusion criteria were identified on the day of surgery by one of the study team members, and the attending anaesthetic team was then informed prior to case commencement to assist in data collection. The attending anaesthetic team was aware that we were conducting a study related to the incidence of pressure related facial ulcers. However, all surgical and anaesthetic management were left to the discretion of the surgeons and anaesthetist. Cases where study members were part of the anaesthetic team and cases which took place on days when study team members were not available to recruit patients were excluded.

All patients were managed perioperatively as per standard clinical care at the discretion of the attending anaesthetist and surgeon. Anaesthesia was typically induced with an intravenous agent (most commonly propofol) and maintained with either an inhalational (desflurane or sevoflurane) or intravenous anaesthetic (propofol infusion). Perioperative pain control was predominantly opioid based with adjuncts such as paracetamol and non-steroidal analgesics. Intraoperative haemodynamics were monitored as per ASA guidelines and managed as indicated. Fluid management was guided by haemodynamic changes and urine output at the discretion of the anaesthetic team. The study team was not involved in the care of study patients at any time.

Data was collected intraoperatively by the attending anaesthetic team and postoperatively by postoperative care nursing unit (PACU) nursing staff. Patient anonymity was maintained throughout the study as no identifiable patient data was collected. Blinding of the abovementioned groups was not possible as knowledge of patient information was required to carry out routine clinical care.

Patient demographics, past medical history and intraoperative details including length and nature of surgery, type of head support and eye protection used, lowest systolic and diastolic blood pressure recorded, usage of forced air warming devices and postoperative tympanic temperature, were also recorded. The duration of surgery was taken as time from skin incision to skin closure.

The presence, location and grade of facial pressure ulcers were noted postoperatively by PACU nursing staff. Facial pressure ulcers were graded according to the National Pressure Ulcer Advisory Panel (NPUAP) staging system as summarised in Table 1.

Table 1: NPUAP pressure ulcer staging system.

\begin{tabular}{|c|c|}
\hline Stage 1 & $\begin{array}{l}\text { Non-blanchable erythema of } \\
\text { intact skin }\end{array}$ \\
\hline Sta & $\begin{array}{l}\text { artial-thickness skin loss with } \\
\text { xposed dermis }\end{array}$ \\
\hline & ss skin lo \\
\hline St & $\begin{array}{l}\text { Full-thickness skin and tissue } \\
\text { loss }\end{array}$ \\
\hline
\end{tabular}

Post-anaesthetic care unit (PACU) nursing staff were briefed prior to study commencement on how to identify prone facial pressures. A coloured pictorial guide was provided to all PACU nursing staff to aid consistent and correct classification. Staging of all pressure ulcers were confirmed by a second PACU nurse. If in doubt, nursing staff could contact study team members for additional clarification.

Data was entered into a secure online electronic database by a member of the study team and was 
subsequently exported to IBM SPSS Statistics for Windows, Version 22.0 (Armonk, NY: IBM Corp. Released 2013) for analysis. An independent statistician was consulted for assistance with data analysis.

Correlation studies were used to identify potential risk factors for the development of facial pressure ulcers. The Wilcoxon rank sum test and univariate logistic regression was used to analyse continuous variables, while the Pearson Chi-Square test was used to analyse categorical variables. Risk factors with a $p$ value equal or less than 0.1 in univariate correlation analysis were then subjected to a multiple logistic model analysis. The cut-off of $p<0.1$ was used in order to include variables which potentially would reach statistical significance on multivariate analysis. Statistical significance was taken as $p<0.05$ after multivariate analysis.

\section{Results}

During our study period, a total of 557 surgeries were done in the prone position, of which 29 were done outside of the major operating theatre and urology complex, 20 were done out of office hours, 53 were emergency cases and one was done under local anaesthesia. Among the remaining 454 cases, we identified and recruited a total of 132 patients.

Eight patients were excluded as head pinning was employed intraoperatively, and a further 10 patients were excluded due to incomplete outcome data. The remaining 114 were included in the final analysis.

The baseline characteristics of the cohort are detailed below in Table 2 .

Table 2: Baseline characteristics of patients undergoing prone position surgery.

\begin{tabular}{|l|l|}
\hline Characteristic & Value \\
\hline Age [mean (range) & $57.3(12-84)$ \\
\hline Male gender (n, percentage) & $58,51.3 \%$ \\
\hline ASA score (n, percentage) & \\
\hline 1 & $11,9.6 \%$ \\
\hline 2 & $77,67.5 \%$ \\
\hline 3 & $26,22.8 \%$ \\
\hline Comorbidities (n, percentage) & \\
\hline Diabetes mellitus & $27,23.7 \%$ \\
\hline
\end{tabular}

\begin{tabular}{|l|l|}
\hline Eczema & $3,2.6 \%$ \\
\hline Current or previous smoking & $14,12.3 \%$ \\
\hline Chronic steroid usage & $5,4.4 \%$ \\
\hline
\end{tabular}

The majority of cases were orthopaedic spine surgeries $(73 \%, 83$ patients), while $25 \%$ (28 patients) of cases were urologic surgeries. General surgical cases completed the remaining $2 \%$ ( 2 patients) of cases; in one case type of surgery was not recorded. Most cases were conducted with the Disposa-View (GE Healthcare, 20 Campus Road, Totowa, New Jersey C7512, USA) as the head support of choice at 97\% (105 patients), while gel donut head rests made up the remaining 3\% (3 patients); head support used was not recorded in 6 cases. Intra- and postoperative parameters recorded are shown below in Table 3 .

Table 3. Intra- and postoperative parameters.

\begin{tabular}{|c|c|}
\hline Characteristic & Value \\
\hline $\begin{array}{l}\text { Duration of surgery, minutes } \\
\text { [mean, (range)] }\end{array}$ & $\begin{array}{l}179 \\
480)\end{array}$ \\
\hline \multicolumn{2}{|l|}{$\begin{array}{l}\text { Type of eye protection used ( } \mathrm{n} \text {, } \\
\text { percentage) }\end{array}$} \\
\hline Micropore $^{\mathrm{TM}}$ tape $^{1}$ & $23,20.2 \%$ \\
\hline Gauze eye pads & $43,37.7 \%$ \\
\hline Tegaderm $^{1}$ & $37,32.5 \%$ \\
\hline Eye-guard tape & $64,56.1 \%$ \\
\hline $\begin{array}{l}\text { Lowest } \mathrm{SBP}, \mathrm{mmHg} \text { [mean, } \\
\text { (range)] }\end{array}$ & $\begin{array}{l}85, \quad(60- \\
121)\end{array}$ \\
\hline $\begin{array}{l}\text { Lowest DBP, mmHg [mean, } \\
\text { (range)] }\end{array}$ & $53,(38-90)$ \\
\hline $\begin{array}{l}\text { Forced air warming device used (n, } \\
\text { percentage) }\end{array}$ & $60,54.5 \%$ \\
\hline $\begin{array}{l}\text { Postoperative tympanic } \\
\text { temperature, degrees Celsius } \\
\text { [mean, (range)] }\end{array}$ & $\begin{array}{l}35.1(33.0- \\
37.3)\end{array}$ \\
\hline
\end{tabular}

Systolic blood pressure, SBP; diastolic blood pressure, DBP.

${ }^{1} 3 \mathrm{M}^{\mathrm{TM}}$, St. Paul, MN 55144, USA

The overall incidence of facial pressure ulcers was $35 \%$. The majority were grade 1 ulcers at $59 \%$, while grade 2 ulcers made up the remaining $41 \%$. The most common locations for facial pressure ulcers were the cheeks $(75 \%)$, followed by the forehead $(43 \%)$, chin $(18 \%)$, eyelids (8\%) and lips (3\%). 
Univariate analysis revealed that female gender (OR 2.39, p=0.031), age (OR 1.03 per year, $\mathrm{p}=0.024)$ and duration of surgery (OR 1.91 per hour, $\mathrm{p}<0.001)$ were associated with an increased risk of developing facial pressure ulcers. Diabetes mellitus (OR 0.34, $\mathrm{p}=0.045$ ) and intraoperative usage of forced air warming devices (OR 0.46, $\mathrm{p}=0.059$ ) were associated with a decreased incidence of facial pressure ulcers. These variables were entered into a multivariate model for analysis to correct for potential confounders.

On multivariate analysis, increased age (OR 1.04 per year, $\mathrm{p}=0.035$ ) and a duration of surgery (OR 2.05 per hour, $\mathrm{p}<0.001$ ) were significantly associated with the development of facial pressure ulcers, but female gender and intraoperative forced air warming device usage as a risk factor did not achieve statistical significance. The presence of diabetes mellitus was associated with a decreased incidence of facial pressure ulcers on multivariate analysis (OR 0.16, $\mathrm{p}=0.028)$.

The incidence of facial pressure ulcers did not significantly differ between surgical disciplines. There were no significant associations between the types of intraoperative eye protection that were used and the occurrence of eyelid pressure ulcers in our post hoc subgroup analysis.

Table 4: Risk factors for facial pressure ulcers.

\begin{tabular}{|c|c|c|c|c|}
\hline \multirow[t]{2}{*}{$\begin{array}{l}\text { Risk } \\
\text { factor }\end{array}$} & \multicolumn{2}{|c|}{ Univariate analysis } & \multicolumn{2}{|c|}{$\begin{array}{l}\text { Multivariate } \\
\text { analysis }\end{array}$} \\
\hline & $\begin{array}{l}\text { OR }(95 \% \\
\text { CI })\end{array}$ & $\begin{array}{l}\mathrm{p} \\
\text { value }\end{array}$ & $\begin{array}{l}\text { OR } \\
(95 \% \mathrm{CI})\end{array}$ & $\mathrm{p}$ value \\
\hline $\begin{array}{l}\text { Female } \\
\text { gender }\end{array}$ & $\begin{array}{l}2.39(1.08- \\
5.27)\end{array}$ & 0.031 & $\begin{array}{l}1.97 \\
(0.70- \\
5.55)\end{array}$ & 0.20 \\
\hline $\begin{array}{l}\text { ASA } \\
\text { score } 2 \\
\text { (versus } 1 \text { ) }\end{array}$ & $\begin{array}{l}1.28(0.31- \\
5.25)\end{array}$ & 0.39 & & \\
\hline $\begin{array}{l}\text { ASA } \\
\text { score } 3 \\
\text { (versus 1) }\end{array}$ & $\begin{array}{l}2.29(0.49- \\
10.6)\end{array}$ & & & \\
\hline $\begin{array}{l}\text { Diabetes } \\
\text { mellitus }\end{array}$ & $\begin{array}{l}0.34(0.12- \\
0.98)\end{array}$ & 0.045 & $\begin{array}{l}0.16 \\
(0.03- \\
0.82)\end{array}$ & 0.028 \\
\hline $\begin{array}{l}\text { Chronic } \\
\text { steroid } \\
\text { usage }\end{array}$ & $\begin{array}{l}1.25(0.20- \\
7.78)\end{array}$ & 0.81 & & \\
\hline $\begin{array}{l}\text { Current } \\
\text { or prior } \\
\text { smoking }\end{array}$ & $\begin{array}{l}1.02(0.32- \\
3.12)\end{array}$ & 0.98 & & \\
\hline $\begin{array}{l}\text { Intraoper } \\
\text { ative } \\
\text { forced air } \\
\text { warming }\end{array}$ & $\begin{array}{l}0.46(0.21- \\
1.03)\end{array}$ & 0.059 & $\begin{array}{l}0.72 \\
(0.25- \\
2.08)\end{array}$ & 0.55 \\
\hline
\end{tabular}

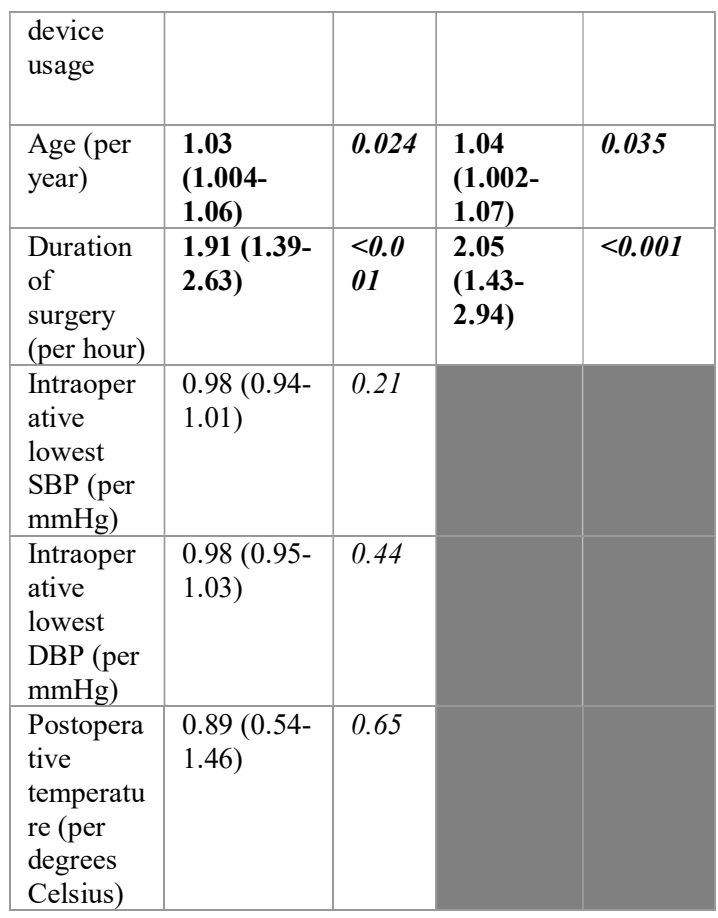

$\mathrm{OR}$, odds ratio. CI, confidence interval.

\section{Discussion}

Our study revealed a significant incidence of facial pressure ulcers in patients undergoing prone surgery - occurring in $35 \%$ of patients across various surgical disciplines. This is significantly higher when compared to many studies among the Caucasian populations. ${ }^{6,7}$ This increased incidence could be related to the difference in the characteristics of Asian skin, where the latter is found to be more prone to exogenous physical and chemical insults arising from a thinner stratum corneum. ${ }^{8}$

The pathogenesis of pressure ulcers in patients undergoing surgery in prone positioning is multifactorial. Tissue ischemia as a result of skin compression against hard surfaces, such as the head support and operating table, is one of the main mechanisms involved. Direct shear stress and friction, combined with the effects of anaesthesia and prolonged immobility, also contribute to the development of pressure ulcers. ${ }^{2-4,6,9}$ Consequently, pressure ulcers most commonly develop on areas in contact with hard surfaces such as bony prominences of the face. For patients undergoing surgery in the prone position, these "at risk" areas include the forehead, nose, malar prominences, chin, acromial processes, breasts, iliac crests, patellae and toes. Indeed, our study shows that the 
cheeks, forehead, chin, eyelids and lips remain the common "at risk" areas for the face.

Our study showed an association of increased age and prolonged duration of surgery with the development of facial pressure ulcers, which is in agreement with existing literature. However, our study showed a divergent result among patients with diabetes mellitus wherein the presence of diabetes mellitus conferred a protective role against the development of facial pressure ulcers. Given that diabetes mellitus is associated with microvascular ischaemia and neuropathy, which predisposes to pressure ulcer development, we postulate that this contrasting result could be a false positive, considering a calculated fragility index of $1 .{ }^{10}$

This is the first study conducted in a tertiary hospital of our local population assessing the incidence of facial pressure ulcers, and to our knowledge the first in South-East Asia. Adequate nursing staff training, distribution of a coloured pictorial guide as well as crosschecking among PACU nurses ensured consistent identification and grading of facial pressure ulcers.

However, our study is not without limitations. Although we did account for some potential confounders in our multivariate statistical analysis, the possibility remains of additional confounders we did not measure which could have affected our results, including anaesthetic factors such as the choice of anaesthetic drug used, duration of hypotension, vasopressor usage as well as patient factors such as ethnicity and body mass index. Due to manpower constraints (one study member was rotated to a different institution midway through the study and was not available to help recruit patients), we only managed to capture $29 \%$ of all prone surgeries done during that time period. This is mitigated by the fact that those cases that were not recruited were evenly distributed among the various disciplines in similar proportions. As this was a non-blinded observational study, the Hawthorne effect, that is, the awareness of being observed, may have altered the anaesthetic management of the patient. Finally, generalisability of the study results may be limited as this study was conducted in a single centre.

Possible directions for future studies may include expanding patient recruitment to multiple centres, both local and regional and/or increasing sample sizes. Interventions which may reduce facial pressure ulcers such as using different head supports, anaesthetic protocols or measures aimed to reduce the duration of prone positioning may also be studied in prospective trials.

\section{Conclusion}

In our local context, patients undergoing surgery in the prone position are at significant risk of developing facial pressure ulcers. Therefore, attention should be paid to intraoperative patient positioning as well as frequent reassessment of skin condition, especially in high-risk populations. Further studies are required to assess possible risk reduction measures and develop a protocol aimed at reducing the incidence of facial pressure ulcers, especially in the susceptible Asian population.

\section{Acknowledgements: None}

Funding: This research received no specific grant from any funding agency in the public, commercial, or not-for-profit sectors.

\section{References}

1. Chen HL, Chen XY, Wu J. The incidence of pressure ulcers in surgical patients of the last 5 years: a systematic review. Wounds. 2012;24:234-41.

2. Lindgren M, Unosson M, Krantz AM, Ek AC. Pressure ulcer risk factors in patients undergoing surgery. J Adv Nurs. 2005;50:605-12. https://doi.org/10.1111/j.13652648.2005.03441.x

PMid:15926965

3. Edgcombe H, Carter K, Yarrow S. Anaesthesia in the prone position. $\mathrm{Br} \mathrm{J}$ Anaesth. 2008; 100:165-83.

https://doi.org/10.1093/bja/aem380

PMid: 18211991

4. Walton-Geer PS. Prevention of pressure ulcers in the surgical patient. AORN J. 2009;89:538-48. https://doi.org/10.1016/j.aorn.2008.12.022 PMid:19269379

5. Edsberg LE, Black JM, Goldberg M, McNichol L, Moore L, Sieggreen M. Revised National Pressure Ulcer Advisory Panel Pressure Injury Staging System: Revised Pressure Injury Staging System. J Wound Ostomy Continence Nurs. 2016;43:585-597. https://doi.org/10.1097/WON.000000000000028 1

PMid:27749790 PMCid:PMC5098472 
6. Grisell M, Place HM. Face tissue pressure in prone positioning: a comparison of three face pillows while in the prone position for spinal surgery. Spine. 2008;33:2938-41. https://doi.org/10.1097/BRS.0b013e31818b9029 PMid:19092629

7. Lee WY, Lin PC, Weng CH, Lin YL, Tsai WL. [A project to reduce the incidence of facial pressure ulcers caused by prolonged surgery with prone positioning]. Hu Li Za Zhi. 2012;59:70-8.

8. Rawlings AV. Ethnic skin types: are there differences in skin structure and function? Int $\mathrm{J}$ Cosmet Sci. 2006;28:79-93. https://doi.org/10.1111/j.14672494.2006.00302.x

PMid: 18492142

9. Jain V, Bithal PK, Rath GP. Pressure sore on malar prominences by horseshoe headrest in prone position. Anaesth Intensive Care. 2007;35:304-5.

10. Kang ZQ, Zhai XJ. The Association between Pre-existing Diabetes Mellitus and Pressure Ulcers in Patients Following Surgery: A Metaanalysis. Sci Rep. 2015;5:13007 https://doi.org/10.1038/srep13007

PMid:26260124 PMCid:PMC4531331 